\title{
Remediation to Restoration \\ to Revitalization: Engaging Communities to Support Ecosystem-Based Management and Improve Human Wellbeing at Clean-up Sites
}

\author{
Kathleen C. Williams and Joel C. Hoffman
}

\begin{abstract}
Remediation to Restoration to Revitalization (R2R2R) is a framework to identify ecological and policy-based relationships between large-scale aquatic sediment remediation projects, subsequent habitat restoration projects, and waterfront revitalization. A defining feature of $\mathrm{R} 2 \mathrm{R} 2 \mathrm{R}$ is that it possesses three essential feedback loops: a translational ecology feedback loop, an adaptive management feedback loop, and a project management feedback loop. The R2R2R framework builds on Ecosystem-Based Management (EBM) theory by addressing the role of humans through these feedback loops, and by recognizing the ability of communities to learn and make choices that improve the environment through translational science. In this framework, translating ecological changes from remediation and restoration projects to public benefits (e.g., swimmable water, potential for urban greenspace) using the concept of ecosystem services is critical to support decisionmaking. In practice, community perceptions and uses of the remediated and restored ecosystem or habitat are central to EBM. We use the Great Lakes Area of Concern program to illustrate how R2R2R exemplifies EBM for large, complex sediment remediation and aquatic habitat restoration projects.
\end{abstract}

\section{Lessons Learned}

- The Remediation to Restoration to Revitalization (R2R2R) framework is integrative of diverse interests through ongoing opportunities for engagement and a synthesis of input to inform research and project alternatives

- Consideration of translational ecology and adaptive management, in addition to the project, create distinct opportunities for engagement with the community, stakeholders, and project implementers

K. C. Williams · J. C. Hoffman $(\bowtie)$

Great Lakes Toxicology and Ecology Division, United States Environmental Protection Agency, Office of Research and Development, Center for Computational Toxicology and

Exposure, Duluth, MN, USA

e-mail: hoffman.joel@epa.gov 
- Health Impact Assessment can create science-based, community-relevant, and decision context relevant recommendations

\section{Needs to Advance EBM}

- Identify relationships between a positive change in environmental stressors, such as sediment contamination and habitat degradation, and improvements in human health or quality of life

- Case studies inclusive of a broad range of environmental management contexts that contribute to our social capacity for inclusive, equitable decision-making in social-ecological systems

\section{Introduction: The R2R2R Framework}

Remediation to Restoration to Revitalization (R2R2R) is a framework to identify ecological and policy-based relationships between large-scale sediment remediation projects, subsequent habitat restoration projects, and community revitalization. Ecological outcomes of remediation and restoration may be defined in terms of either ecological quality (e.g., a sediment quality target) or quantity (e.g., acres of wetland restored; Krantzberg 2003). Revitalization outcomes promote humanwellbeing, including social equity, while protecting or improving natural capital (Angradi et al. 2019). However, as a social-ecological system, the connections and feedbacks between remediation, restoration, and revitalization are not wellunderstood. In the Great Lakes region, remediation and restoration projects along urban waterfronts changed people's interactions with urban, aquatic ecosystems. For example, after projects were complete, increased use of trails and waterways, and changes in economic activity and land uses, improved people's quality of life (Krantzberg 2012; Hartig et al. 2019; Williams and Hoffman in review). However, a framework to identify the connection and feedbacks that led to the change in quality of life has not been available to researchers or managers. This impedes achieving a broader goal of maximizing ecological outcomes and social benefits to human well-being. Therefore, our goal was to develop this framework, recognizing that it should incorporate principles of Ecosystem-Based Management (EBM).

We developed R2R2R in the context of the Great Lakes Area of Concern (AOC) Program. The U.S.-Canada Great Lakes Water Quality Agreement (Annex 1, 2012) defines Areas of Concern as "geographic areas that fail to meet the general or specific objectives of the agreement where such failure has caused or is likely to cause impairment of beneficial use of the area's ability to support aquatic life." When the program was initiated in 1987, 43 AOCs were identified, 31 of which were entirely or partly in U.S. waters. Most AOCs are located near population centers, are within the Great Lakes coastal zone, and are degraded by legacy contaminants including heavy metals and persistent organic pollutants (Hartig et al. 2019). The program recognizes 14 distinct beneficial use impairments (BUIs). Nearly all AOCs have multiple impaired beneficial uses, which arise from multiple causes including sediment and water contamination, habitat loss, excess nutrients and sediment 
inputs, and improperly functioning storm or sewer systems (Hartig and Zarull 1992). It is common for Superfund sites to be located within an AOC, and for brownfields to be located nearby. The AOC program's goal is to remove BUIs through contaminated sediment remediation, aquatic habitat restoration, or both. In AOC communities, revitalization is primarily targeted towards urban waterfronts, and is inclusive of policies or actions on waterfronts or in adjacent aquatic areas.

Our objective is to describe the R2R2R framework and demonstrate how it builds upon EBM theory. We anticipate the R2R2R framework can be applied broadly to the problem of remediation, for example in brownfields or Superfund programs (Lipps et al. 2017) and recognize that important details of implementation will depend on each program's requirements and legal authorities. For example, under the Comprehensive Environmental Response, Compensation, and Liability Act (CERCLA, also known as Superfund), the definition of natural resources and the criterion for future use (e.g., residential) will influence remediation, restoration, and revitalization decisions (Burger 2008). For the purposes of this chapter, we will speak of R2R2R in general terms, and provide examples specific to the Great Lakes AOC program. We conclude with a case study which illustrates that integrating social and ecological knowledge is possible by integrating a formal decision-support system (Health Impact Assessment) designed to consider diverse knowledge and values into the R2R2R framework.

\section{R2R2R Framework as a Decision-Support System}

The R2R2R framework describes a process for achieving management goals and project objectives within a social-ecological system (Fig. 1). Generally, R2R2R sites involve substantial engineering to address ecological stressors causing identified ecological impairments. Community members, stakeholders, and agencies choose the acceptable ecological or human risk at the remediation site, the type and quantity of habitats to be restored (within biological constraints), and the future uses and activities that will occur at the site (Krantzberg 2003). Because it is an engineered project within a community, the ecosystem undergoing remediation and restoration is embedded within a social system which may be organized by neighborhoods, user groups, municipalities, and state, federal, and tribal agencies. It is a flexible, adaptive system that is built upon, and responsive to, diverse community members and organizations. As such, R2R2R can also be described as an adaptive co-management system (Folke et al. 2002). As with adaptive co-management, R2R2R focuses on specific places (AOCs) and environmental stressors (BUIs), and emphasizes learning through management actions, adaptively evolving management activities and governance (Dietz et al. 2003; Olsson et al. 2004).

A defining feature of R2R2R is its three feedback loops: a translational ecology (TE) feedback loop, an adaptive management (AM) feedback loop, and a project management (PM) feedback loop (Fig. 1). As illustrated, the R2R2R framework is cyclical and iterative, and thereby explicitly recognizes ecological and social 


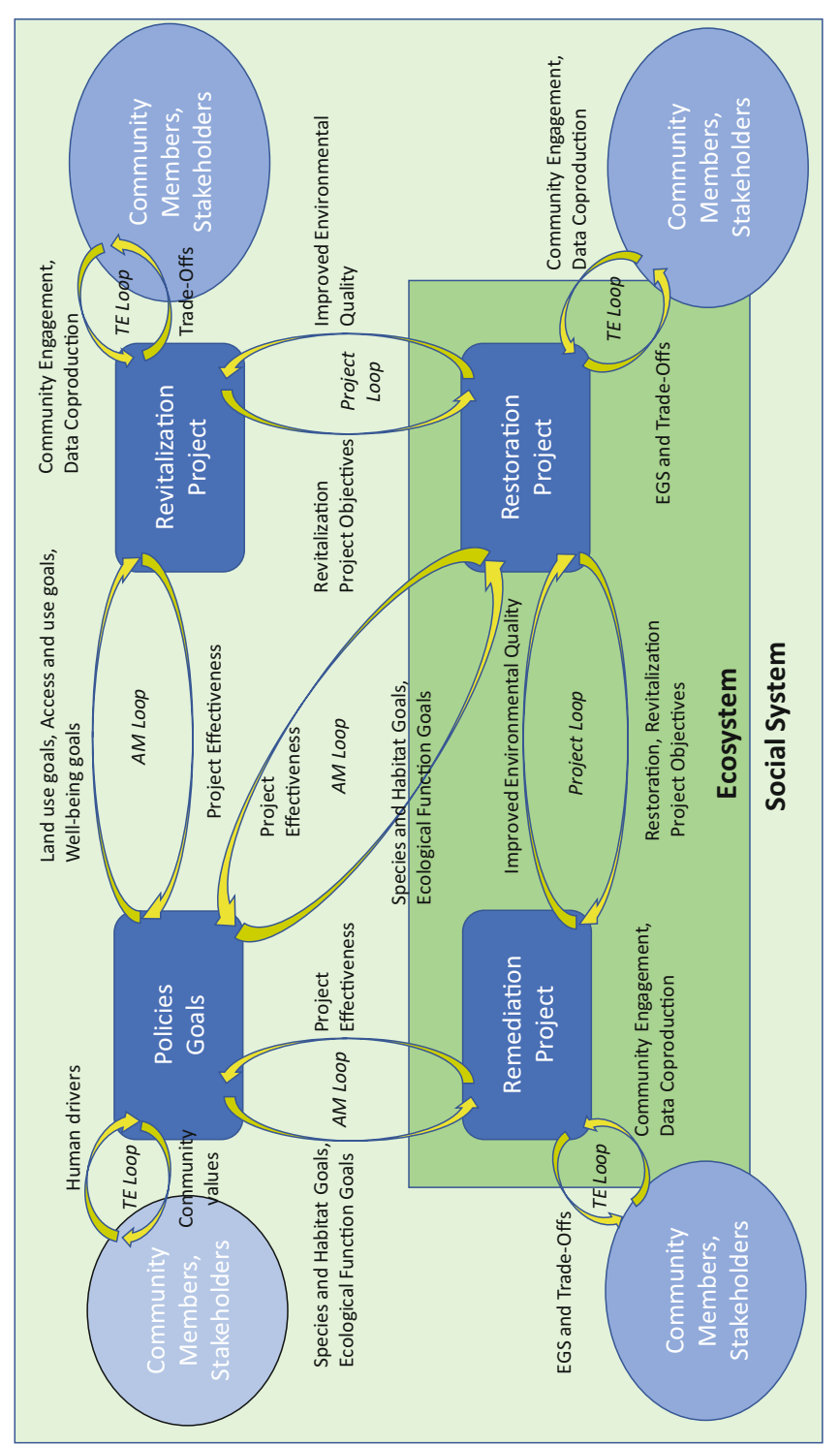

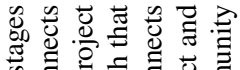

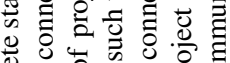

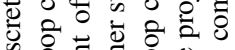

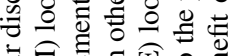

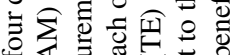

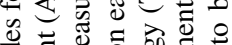

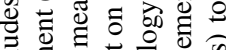
워용

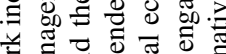
큼 ว

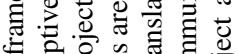
\&

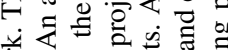

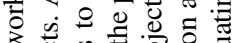

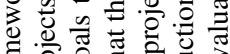

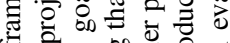

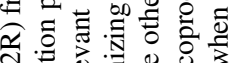

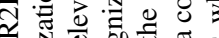

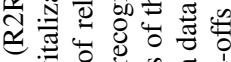
ธิ

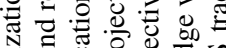
吾

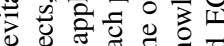

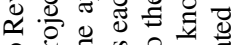
을

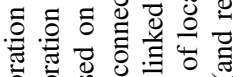
เั

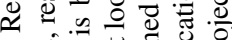

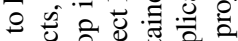

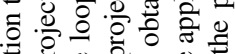

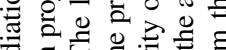

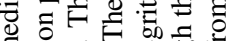

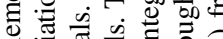

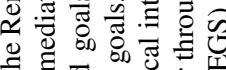
巳 ¿०

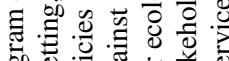

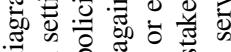

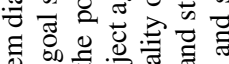
荡 क ज

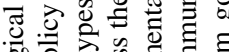

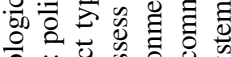

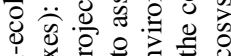

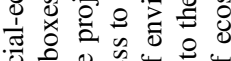
जั०

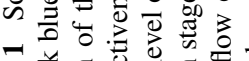

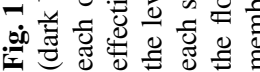


complexity and interactions. For example, the cycle could begin with a plan for revitalization, which in turn may spark community, stakeholder, or decision-maker interest in remediation and restoration. These feedback loops are linked. For example, the TE and AM feedback loops intersect during community engagement as the community helps to define the project ecological and social goals.

In translational ecology (TE), scientists and community members collectively identify ecological and social goals, and address problems related to both environment and society (Enquist et al. 2017). Translation is built on knowledge exchange between scientists and stakeholders, and thereby promotes mutual learning. This approach is shared with EBM (Slocombe 1998) and is inherent to the design the Great Lakes AOC program (Krantzberg 2012). The R2R2R framework requires an iterative, participatory TE process that is dynamic and adaptive because the underlying ecological system is complex and the social system includes agencies, non-government organizations, and socio-economically diverse communities. For AOCs, R2R2R is inherently translational; when their original Remedial Action Plans (RAPs) were created in the late-1980s, state agencies were advised by scientists, local governments, and community members (Botts and Muldoon 2005; Hartig and Zarull 1992). The TE feedback loop ideally continues through four discrete stages of the R2R2R process (policies and goals, and remediation, restoration, and revitalization projects; Fig. 1). Scientists engage with community members and stakeholders to gather knowledge and co-produce scientific data, which are translated into potential ecosystem goods and services (EGS), with associated benefits or losses (trade-offs) identified based on project alternatives (e.g. Martin et al. 2018; DeWitt et al. 2020). This information is provided to decision-makers, and their decision in turn affects researchers and community members (Daily et al. 2009; Wall et al. 2017). In TE, a wide range of stakeholders and community members are included. To address related environmental justice concerns, extra effort may be required to engage under-represented and vulnerable populations that are directly or indirectly affected by the contaminated site (Geller et al. 2016).

In the adaptive management (AM) feedback loop, periodic evaluations based on project-effectiveness metrics determine whether the project is meeting identified targets relative to either goals (program or policy scale) or objectives (project scale; Slocombe 1998). If those goals are not met, decision-makers must modify the project to address identified shortcomings, and the cycle of evaluation and modification continues (e.g., McLain and Lee 1996). If decision-relevant endpoints are chosen that convey value to the public regarding the ecosystem services gained or lost through the remedy (e.g., water of sufficient quality to use, fish of sufficient quality to safely consume) or restoration (e.g., wetlands of sufficient quality to support ecologically sensitive, charismatic species), metrics can potentially be used for both public communication and in a translation ecological context (Allan et al. 2015; Angradi et al. 2016; Olander et al. 2017; Wall et al. 2017). Ideally, within the $\mathrm{AOC}$ program, $\mathrm{AM}$ for remediation and restoration projects begins with discrete management actions to support project implementation, followed by project implementation, monitoring, and evaluation, and ultimately (if impairments are successfully removed) AOC delisting. In between the time when all identified management 
actions are complete and delisting, there is opportunity for the AOC community (including state agencies, citizen advisory committee, and potentially stakeholders and community members) to address additional remediation and restoration needs as necessary.

Remediation goals are developed by evaluating the risk or impact to the ecosystem from chemical exposure, which can be accomplished formally though ecological risk assessment or through other evaluations to determine ecosystem impairments (Burger 2008). Remedy effectiveness is an approach to determine whether remediation goals are met, wherein physical, chemical, and biological lines of evidence (LOE) are measured prior to, potentially during, and after remediation (e.g., Meier et al. 2015). Multiple LOE such as sediment or porewater contaminant concentration, toxicity tests, contaminant bioaccumulation, indices of biotic integrity, or bioassays are measured to evaluate the ecosystem response. Ideally, at least some LOE have associated targets (i.e., a desired value post-remediation).

Restoration effectiveness is an emerging concept within the R2R2R framework. We assume here that the remediation project has at least some ecosystem restoration goals. The purpose of restoration is to address ecological stressors and in the context of the AOC program, which is focused on riverine, coastal, and riparian habitats, these stressors include aquatic habitat loss or degradation, sedimentation or erosion, and invasive species (Hartig and Zarull 1992). In R2R2R, identified ecological goals include multiple species and habitats, and may address supporting ecological functions (e.g., nutrient cycling or fish spawning habitat). The topic of developing habitat restoration targets has been addressed at-length (e.g., Ruiz-Jaen and Aide 2005; Palmer et al. 2005). Some targets, such as water quality criteria, must specifically address program needs. Other targets which are ecologically relevant (i.e., an index of biotic integrity or metric of stress) and devised for various levels of biological organization (species to ecological community) may support AM decisions.

Revitalization effectiveness is a relatively new concept in Great Lakes AOCs. Remediation has economic benefits, which have been measured in AOCs by hedonics and economic impact analysis (e.g., Isely et al. 2018). For R2R2R, revitalization is best understood as a positive change in community wellbeing (Krantzberg 2003). Community-level social and economic changes can occur in concert with remediation and restoration efforts (Krantzberg 2012). For example, AOC practitioners associate remediation with positive social changes, including increased recreational use of the waterfront and changes in land use or waterfront business (Williams and Hoffman in review). While environmental, economic, social, and governance metrics have been proposed (Angradi et al. 2019), few formal studies exist that demonstrate broad-based changes in community wellbeing or quality of life (Krantzberg 2012).

The PM feedback loop recognizes that the community and scientists may identify project-specific goals that require certain ecological targets to be met at the preceding step. Often, risk assessment, remediation, and restoration are conducted separately and independently; however, integration can achieve efficiencies in terms of time and energy (Burger 2008). In the R2R2R framework, we postulate that integration can yield a greater ecological and social impact than would be achieved by 
conducting remediation, restoration, and revitalization projects separately. However, we are not aware of studies evaluating the relative success of integrating these elements.

\section{$3 \quad$ R2R2R and Ecosystem-Based Management}

As a framework, R2R2R shares foundational elements with Ecosystem-Based Management (EBM; Grumbine 1994; Arkema et al. 2006; Ruckelshaus et al. 2008). These qualities include that it is normative (reflects specific values), principled (aims to improve public good), integrative of different interests by synthesizing a wide range of information and knowledge garnered through engagement and participation, accommodating of complexity and change through feedback loops, is explainable to a wide group of people through the translational ecology loop, and is adaptive (Box 1; Slocombe 1998). In R2R2R, project workflow is relational and directional, such that the outcomes of the last stage (revitalization) are linked to both the initial conditions and success of prior stages (remediation and restoration). As such, ideally, discussions regarding all three stages and the associated projects.

\section{Box 1 Principles of the Remediation to Restoration to Revitalization Framework \\ Ecological integrity and sustainability}

To restore ecological integrity, the program adheres to a sustainable relationship between humans and ecosystems recognizing that the capacity of ecosystems to support life has been substantially diminished because of human actions (i.e., ecological impairments). An important outcome is the creation or restoration of the cultural, spiritual, or experiential relationship between people and the river.

\section{Spatial planning}

The spatial distribution of people, resources, and ecosystems is critical to R2R2R. Remediation and restoration are spatially-specific activities that occur within a landscape mosaic of human and ecological communities. Sediment contamination and aquatic habitat loss or degradation are spatially discrete and heterogeneously distributed, though stressors may occur at larger spatial scales. The built environment is amenable to spatial planning.

\section{Effectiveness metrics}

Effectiveness metrics inform whether remediation, restoration, and revitalization project objectives are met. Adaptive management can occur in ecological and social domains, and therefore metrics and pre- and post-project monitoring should occur in both domains. 


\section{Box 1 (continued)}

Remediation, restoration, and revitalization adaptively linked

Objectives and outcomes of remediation, restoration, and revitalization projects flow from one project to another, and thus success is interlinked. While remediation and restoration objectives are often established by government agencies, because revitalization objectives are community-based, community values and use objectives can inform remediation and restoration objectives.

\section{Agency of people}

Where science and policy knowledge are produced together, the process undertaken to engage stakeholders and the public matters. In the context of decision-support (e.g., health impact assessment), collaborative group processes facilitate mutual learning. Trust and legitimacy, which are founded on facilitation and knowledge sharing, are important for project success.

Social system integral to the framework

The translational feedback loop integrates community values and knowledge with scientific knowledge to inform project objectives, which in turn aims to improve provisioning of ecosystem services for community wellbeing. Recommendations to achieve ecological and social goals arise from community members, stakeholders, and scientists, and are responsive to policy goals (e.g., removal of ecological impairments).

\section{Participatory process that integrates different kinds of knowledge}

Translational ecology is used to integrate scientific, local, and traditional ecological knowledge using participatory processes that adhere to principles of democracy, collaboration, communication, and equity. The participatory process is organized as a cooperation among individuals, nongovernment organizations, municipalities, and state, federal, and tribal agencies working at neighborhood, city, reservation, and state scales.

In R2R2R, as with EBM, ecosystem services provisioning is fundamental to sustainability over time (Levin and Lubchenco 2008). Ecosystem goods and services (EGS) are outputs of nature that contribute to human wellbeing when consumed, used, or enjoyed (Bruins et al. 2017). Coastal wetlands and river mouth estuaries (Larson et al. 2013), the most common habitat impacted in AOCs, provide a diverse array of ecosystem services (Sierszen et al. 2012). Beneficial use impairments in AOCs such as fish consumption advisories, beach closings, or dredging restrictions represent ecosystem services loss. Moreover, EGS respond directly to alteration of the biophysical state of the AOC (Yee et al. 2020), provide a consistent and comprehensive set of benefits for consideration, and can be mapped or quantified to illustrate trade-offs to the public (Angradi et al. 2016).

It is important to recognize in Fig. 1 the relationships between ecological integrity and ecosystem services on the ecosystem side, and wellbeing and equity on the social system side (Schoeman et al. 2014; Piet et al. 2020). An accounting of 
ecosystem services can provide measures of community benefits that may not be easily recognized (Olander et al. 2017). By embedding EGS as the connection to wellbeing and equity, we recognize trade-offs are central to decision-making (Angradi et al. 2016; Martin et al. 2018). As such, recommendations can be made to ensure that impacts do not disproportionately affect under-represented, disadvantaged, and vulnerable groups. Here again, we need decision support processes that integrate different kinds of knowledge, including traditional ecological knowledge (Berkes et al. 2000), recognize the importance of social inclusiveness, and provide recommendations to improve equity.

It is also important to recognize that the restored ecosystem and community are embedded within larger systems, such as a watershed and state, respectively. This external relationship may present concerns related to resiliency, reversibility, source control, long-term stewardship, or other factors that arise from outside the control of the project area or community and which need to be addressed as part of the solution (Adger et al. 2005; Levin and Lubchenco 2008; Palumbi et al. 2008). The Great Lakes AOC program can address AOC-specific structural goals (habitat amount, cultural features) and organizational goals (ecological productivity or connectivity, human use and development), but can only contribute to process goals (biodiversity and evolutionary complexity, quality of life; Slocombe 1998), which are driven by large-scale stressors (e.g., Allan et al. 2015).

One of the animating questions in EBM, and in R2R2R, is who will do this work? Substantial challenges exist with respect to our understanding of social-ecological systems for implementing integrated solutions. For example, social dimensions of social-ecological systems remain poorly defined (Brown 2009, 2014), and when considered are limited to studies of scale, governance, and institutions (Brown 2014; Turner 2014). Moreover, the focus on "the functionality of institutions and ...normative issues as outcomes," instead of as integral parts of the system (Cote and Nightingale 2012) minimizes the attention given to relations of power, diverging interests, and social identities (Brown 2014; Turner 2014) that often challenge the creation of sustainable solutions. In R2R2R practice, we therefore ask, "what is the role of scientists, decision-makers and managers, public advisor groups, and citizens?" Are roles clarified, aligned, and sufficiently supported for R2R2R to be successful? How do we address ongoing conflict between government processes that traditionally rely on technological knowledge versus community processes that rely on integrated knowledge? Current environmental management practice often treats these different interests as competing, but an agonist approach (Mouffe 1999) suggests that finding ways to treat these different types of knowledge as equal can be productive (Cote and Nightingale 2012). To address the underlying drivers of environmental degradation, we need to engage community morals and values, as well as promote shared benefits of revitalization (Groenfeldt and Schmidt 2013; Daigneau 2015). This is where TE principles (collaboration, engagement, commitment, communication, process, and decision-framing) are critical to connect research and practice (Lawson et al. 2017; Wall et al. 2017).

R2R2R can address potential shortcomings with respect to community engagement that can occur in EBM (Krantzberg 2003). It does so by stipulating community 
engagement and translational science to occur at each part of the process, recognizing that different community groups may be engaged with and impacted by each part of the process differently. We postulate that for R2R2R to be successful, there must be a translational component that facilitates learning given that remediation and restoration projects generally rely on scientific or technological knowledge (Cote and Nightingale 2012; Partidario and Sheate 2013). To do so requires a decisionsupport process that follows TE principles and is based on constructivist learning theory, such as impact assessment (e.g., health impact assessment; Partidario and Sheate 2013) or structured decision-making (Sharpe et al. 2020). For implementation, R2R2R requires concepts and strategies from social science that aim to span the boundary between scientific knowledge and decision-making (Mollinga 2010; Williams 2015). Next, we demonstrate how using a constructivist approach can yield a broad range of potential political solutions and recommendations through community engagement (Cote and Nightingale 2012; Evans 2011). The following case study explores how this engagement may produce an integrated solution.

\section{Implementing R2R2R Case Study}

The U.S. Environmental Protection Agency designated the St. Louis River Area of Concern (AOC) in 1987 owing to historical degradation including discharge of untreated wastewater and debris from industrial and municipal facilities (MPCA and WDNR 1992). The AOC includes the lower $63 \mathrm{~km}$ of the St. Louis River. The port cities of Duluth, Minnesota and Superior, Wisconsin are situated at the river's mouth where it flows into Lake Superior. With respect to sediment contamination, chemicals of concern include polychlorinated biphenyls (PCBs), polychlorinated dibenzodioxins (PCDDs, or dioxins), polychlorinated dibenzofurans (PCDFs, or furans), polyaromatic hydrocarbons (PAHs), and heavy metals, all of which are present at multiple locations in the AOC (Crane et al. 2005). State (Minnesota, Wisconsin) and tribal (Fond du Lac Band of Lake Superior Chippewa) agencies coordinate sediment remediation and habitat restoration projects. In Duluth, the neighborhoods adjacent to the river were once home to numerous saw mills, coal tar processing facilities, and steel mills, but today are suffering from poverty and poor health outcomes (Williams et al. 2019).

With sediment remediation underway, the City of Duluth is revitalizing the "St. Louis River Corridor" through the development of active recreation opportunities including trails, regional parks, and improved access to the river in these same neighborhoods (City of Duluth 2018). The AOC and community revitalization processes intersect at the Kingsbury Bay and Grassy Point habitat restoration project. Kingsbury Bay is adjacent to a city park and campground that is also a historical Native American camp, along which a riverfront trail will be improved. Grassy Point is city-owned green space along the riverfront; it is a wetland complex and has an unimproved boat launch and a wetland boardwalk with a fishing pier that are in 
disrepair. Kingsbury Bay is impacted by long-term excess sedimentation that resulted in aquatic habitat loss. Grassy Point was the location of two former saw mills, resulting in sediment contamination from both wood wastes and dioxins. The two sites are about $2 \mathrm{~km}$ apart, and the combined project covers about $1 \mathrm{~km}^{2}$ of river and involves dredging $268,000 \mathrm{~m}^{3}$ of sediment. The restoration will beneficially use sediment dredged from Kingsbury Bay to build habitat at Grassy Point Park, while remediation work as Grassy Point includes wood waste removal and covering contaminated sediments. The project will improve river access in economicallydisadvantaged neighborhoods with poor access (USEPA 2019). Project objectives include adding a river trail, a swimming beach, canoe and kayak landings, boardwalks, fishing piers, and interpretative signage. The project area also has potential for supporting plants including wild rice that are culturally important to indigenous people.

Recognizing the complexity of design decisions, project implication for the health of adjoining neighborhoods, and a diversity of community members and stakeholders, we conducted a health impact assessment (HIA) to create evidencebased recommendations to inform the Minnesota Department of Natural Resources project design (i.e., sediment remediation and aquatic habitat restoration) and the City of Duluth park planning (i.e., site access and amenities). Health impact assessment (HIA) is a systematic process that uses a variety of data sources and community and stakeholder consultation to ascertain potential health impacts of a policy change or decision, and to make recommendations that mitigate negative health impacts or enhance positive health impacts (National Research Council 2011). Health impact assessment is built upon democratic participation, health equity, and a comprehensive approach to health (i.e., community wellbeing; Quigley et al. 2006). Further, HIA assumes the community is a stakeholder (Human Impact Partners 2011), which is important given a lack of consensus regarding long-term plans for redevelopment along the river (Johnston et al. 2017).

The inclusion of community input early in the process ensures community values are considered at a point when values can influence recommendations provided as part of the HIA (Iroz-Elardo 2014). In the Kingsbury Bay-Grassy Point habitat restoration project, we started the process with two introductory meetings for stakeholders, one for the general public and one for group representatives (i.e., city planners, non-government organizations, and natural resource managers). The meetings were nearly identical and included an introduction to HIA, an overview of the project, and opportunities for discussion and input. To ensure opportunities for meaningful inclusion, we captured different types of knowledge and experience. Participants in both meetings were invited to share their experiences with the two sites by placement of sticky notes on project maps, and to explain how the changes would impact their daily lives or experiences (Boschmann and Cubbon 2014; Johnston et al. 1995). The submitted comments reflected a variety of personal and professional experiences and conveyed individual perspectives regarding sense of place and identity. Comments included concern about park maintenance, safety, 
access, traffic, invasive species management, disturbance of an adjacent Superfund site, and identified opportunities for social gathering, birding, fishing, and boating.

Health impact assessment is designed to mediate power relations through an inclusionary and iterative process. In the Kingsbury Bay-Grassy Point habitat restoration project HIA, all submitted comments were analyzed to identify the social and environmental determinants of health and wellbeing valued by community members and stakeholders (Marmet et al. 2008). This community-based information was used to construct health pathways, which identify how project elements are likely to effect health outcomes. We identified impacted ecosystem services to relate the proposed biophysical changes at the site to public-friendly endpoints such as swimmable water or edible fish, and then to health benefits. Transparency was ensured throughout the process through ongoing communication and opportunities for input. Detailed meeting notes that include all comments, questions, and participants were distributed after each meeting, and community members and stakeholders could make suggestions or corrections to any set of notes produced. Community members and stakeholders were invited to participate in technical and community committees that advise the HIA through each step.

In total, the HIA yielded 77 unique recommendations to improve project health outcomes. Recommendations addressed trail safety, environmental quality, cultural resources, and social places for gathering. Recommendations also addressed the ecological quality of the project, including to protect existing high-quality wetlands and to implement invasive species controls. Importantly, the process was widely endorsed by community members, stakeholders and decision-makers as positive and constructive. We found that HIA is helpful in the AOC context because it provides a means to explore how sediment remediation, habitat restoration, and park management are interrelated, and how this will collectively impact community health as defined by community members and stakeholders. In this case study, the HIA informed both final landscape design for habitat restoration and will be included in future park master planning.

Broadly, HIA integrates with the three loops of R2R2R, and therefore may be widely useful. In this case study, HIA served as a formal approach to decision support that facilitated translational science. Other decision support approaches might also be used to support TE (e.g., Sharpe et al. 2020). The TE loop included the community through engagement and data co-production; community knowledge was foundational to the science-based pathways for impact analysis. The AM loop related HIA recommendations to restoration projects and city park plans, which changed in response to research and collective discussions about the value of Kingsbury Bay and Grassy Point Park. Finally, the PM loop linked revitalization outcomes such as safe swimming beaches and birdwatching opportunities to ecosystem services that were necessary to restore through remediation and restoration. 


\section{Conclusions}

It has long been recognized that successful implementation of an ecosystem approach to integrate environmental and social decision-making requires attention to both the substance and process of the approach (Slocombe 1993; McLain and Lee 1996). The R2R2R framework builds on EBM theory by addressing the role of humans (e.g., natural resource agencies, community members) through multiple feedback loops, and recognizing their ability to learn and make choices that improve the environment through translational science. We demonstrate that integrating social and ecological knowledge is possible by utilizing the R2R2R framework with a specific process (HIA) designed to consider diverse knowledge and values. Ecosystem-Based Management is difficult because the benefits humans and society derive from ecosystem processes cannot be viewed as objectively existing "out there," but as entangled in social and political processes (Ernston 2013). The R2R2R framework provides interlinking loops of translational ecology, adaptive management, and project management as a system for integrating these diverse processes. As a community of practice, R2R2R is relatively new, and we anticipate that ongoing remediation and restoration efforts in the Great Lakes and elsewhere will contribute to our social capacity for inclusive, equitable decision-making in social-ecological systems.

Disclaimer This chapter has been subjected to Agency review and has been approved for publication. The views expressed in this paper are those of the author(s) and do not necessarily reflect the views or policies of the U.S. Environmental Protection Agency.

\section{References}

Adger, W. N., Hughes, T. P., Folke, C., Carpenter, S. R., \& Rockström, J. (2005). Social-ecological resilience to coastal disasters. Science, 309, 1036-1039.

Allan, J. D., Smith, S. D., McIntyre, P. B., Joseph, C. A., Dickinson, C. E., Marino, A. L., Biel, R. G., Olson, J. C., Doran, P. J., Rutherford, E. S., \& Adkins, J. E. (2015). Using cultural ecosystem services to inform restoration priorities in the Laurentian Great Lakes. Frontiers in Ecology and the Environment, 13, 418-424.

Angradi, T. R., Launspach, J. J., Bolgrien, D. W., Bellinger, B. J., Starry, M. A., Hoffman, J. C., Trebitz, A. S., Sierszen, M. E., \& Hollenhorst, T. P. (2016). Mapping ecosystem service indicators in a Great Lakes Area of Concern. Journal of Great Lakes Research, 42, 717-727.

Angradi, T. R., Williams, K. C., Hoffman, J. C., \& Bolgrien, D. W. (2019). Goals, beneficiaries, and indicators of waterfront revitalization in Great Lakes Areas of Concern: A natural capital perspective. Journal of Great Lakes Research, 45, 815-863.

Arkema, K. K., Abramson, S. C., \& Dewsbury, B. M. (2006). Marine ecosystem-based management: From characterization to implementation. Frontiers in Ecology and the Environment, 4, $525-532$.

Berkes, F., Colding, J., \& Folke, C. (2000). Rediscovery of traditional ecological knowledge as adaptive management. Ecological Applications, 10, 1251-1262. 
Boschmann, E. E., \& Cubbon, E. (2014). Sketch maps and qualitative GIS: Using cartographies of individual spatial narratives in geographic research. The Professional Geographer, 66, 236-248.

Botts, L., \& Muldoon, P. R. (2005). Evolution of the Great Lakes water quality agreement. Michigan State University Press.

Brown, K. (2009). Human development and environmental governance: A reality check. In W. N. Adger \& A. Jordan (Eds.), Governing sustainability (pp. 32-51). London: Cambridge University Press.

Brown, K. (2014). Global environmental change I: A social turn for resilience? Progress in Human Geography, 38, 107-117.

Bruins, R. J., Canfield, T. J., Duke, C., Kapustka, L., Nahlik, A. M., \& Schäfer, R. B. (2017). Using ecological production functions to link ecological processes to ecosystem services. Integrated Environmental Assessment and Management, 13, 52-61.

Burger, J. (2008). Environmental management: Integrating ecological evaluation, remediation, restoration, natural resource damage assessment and long-term stewardship on contaminated lands. Science of the Total Environment, 400, 6-19.

City of Duluth. (2018). St. Louis river corridor: Connecting people to the river. Retrieved from http://duluthmn.gov/media/543434/final-stlouis-river-corridor-brochure-2018.pdf.

Cote, M., \& Nightingale, A. J. (2012). Resilience thinking meets social theory: Situating social change in socio-ecological systems (SES) research. Progress in Human Geography, 36, 475-489.

Crane, J. L., Richards, C., Breneman, D., Lozano, S., \& Schuldt, J. A. (2005). Evaluating methods for assessing sediment quality in a Great Lakes embayment. Aquatic Ecosystem Health and Management, 8, 323-349.

Daigneau E. (2015). Just green enough. Governing. [online]. Retrieved from https://www. governing.com/topics/transportation-infrastructure/gov-green-gentrification-series.html.

Daily, G. C., Polsaky, S., Goldstein, J., Kareiva, P. M., Mooney, H. A., Pejchar, L., Ricketts, T. H., Salzman, J., \& Shallenberg, R. (2009). Ecosystem services in decision making: Time to deliver. Frontiers in Ecology and the Environment, 7, 21-28.

DeWitt, T. H., Berry, W. J., Canfield, T. J., Fulford, R. S., Harwell, M. C., Hoffman, J. C., Johnston, J. M., Newcomer-Johnson, T. A., Ringold, P. L., Russel, M. J., Sharpe, L. A., \& Yee, S. J. H. (2020). The final ecosystem goods and services (FEGS) approach: A beneficiarycentric method to support ecosystem-based management. In T. O’Higgins, M. Lago, \& T. H. DeWitt (Eds.), Ecosystem-based management, ecosystem services and aquatic biodiversity: Theory, tools and applications (pp. 127-148). Amsterdam: Springer.

Dietz, T., Ostrom, E., \& Stern, P. L. (2003). The struggle to govern the commons. Science, 31, 1907-1912.

Enquist, C. A. F., Jackson, S. T., Garfin, G. M., Davis, F. W., Gerber, L. R., Littell, J. A., Tank, J. L., Terando, A. D., Wall, T. U., Halpern, B., Hiers, J. K., Morelli, T. L., McNie, E., Stephenson, N. L., Williamson, M. A., Woodhouse, C. A., Yung, L., Brunson, M. W., Hall, K. R., Hallett, L. M., Lawson, D. M., Moritz, M. A., Nydick, K., Pairis, A., Ray, A. J., Regan, C., Safford, H. D., Schwartz, M. W., \& Shaw, M. R. (2017). Foundations of translational ecology. Frontiers in Ecology and the Environment, 15, 541-550.

Ernston, H. (2013). The social production of ecosystem services: A framework for studying environmental justice and ecological complexity in urbanized landscapes. Landscape and Urban Planning, 109, 7-17.

Evans, J. P. (2011). Resilience, ecology and adaptation in the experimental city. Transactions of the Institute of British Geographers, 36, 223-237.

Folke, C., Carpenter, S., Elmqvist, T., Gunderson, L., Holling, C. S., \& Walker, B. (2002). Resilience and sustainable development: Building adaptive capacity in a world of transformations. Ambio A Journal of the Human Environment, 31, 347-440.

Geller, A. M., Breville, M., Eisenhauer, E., Sykes, K., Fulk, F., Quackenboss, J., Zartarian, V., Jarabeck, A., Lee, C., Manibusan, M., Oxendine, S., Snyder, E., \& Williams, K. (2016). 
Environmental justice research roadmap, EPA/601/R-16/006. Washington, DC: U.S. Environmental Protection Agency.

Groenfeldt, D., \& Schmidt, J. J. (2013). Ethics and water governance. Ecology and Society, 18, 14. Grumbine, R. E. (1994). What is ecosystem management? Conservation Biology, 8, 27-38.

Hartig, J. H., \& Zarull, M. A. (1992). Under RAPs: Toward grassroots ecological democracy in the Great Lakes basin. Ann Arbor: University of Michigan Press.

Hartig, J. H., Krantzberg, G., Austin, J. C., \& McIntyre, P. M. (2019). Great lakes revival: How restoring polluted waters leads to rebirth of Great Lakes communities. Ann Arbor: International Association of Great Lakes Research.

Human Impact Partners. (2011). A health impact assessment toolkit: A handbook for conducting HIA (3rd ed.). Oakland: Human Impact Partners.

Iroz-Elardo, N. (2014). Health impact assessment as community participation. Community Development Journal, 50, 280-295.

Isely, P., Isely, E. S., Hause, C., \& Steinman, A. D. (2018). A socioeconomic analysis of habitat restoration in the Muskegon Lake area of concern. Journal of Great Lakes Research, 44, 330-339.

Johnston, R. J., Weaver, T. F., Smith, L. A., \& Swallow, S. K. (1995). Contingent valuation focus groups: Insights from ethnographic interview techniques. Agricultural and Resource Economics Review, 24, 56-69.

Johnston, J. M., de Jesus Crespo, R., Harwell, M. C., Jackson, C., Myer, M., Seeteram, N., Williams, K., Yee, S., \& Hoffman, J. (2017). Valuing community benefits of final ecosystem goods and services: Human health and ethnographic approaches as complements to economic valuation, EPA/600/R-17/309. Washington, DC: U.S. Environmental Protection Agency.

Krantzberg, G. (2003). Keeping remedial action plans on target: Lessons learned from Collingwood Harbor. Journal of Great Lakes Research, 29, 641-651.

Krantzberg, G. (2012). First off the list: The Collingwood Harbour study. In V. I. Grover \& G. Krantzberg (Eds.), Great Lakes: Lessons in participatory governance (pp. 257-267). Boca Raton: CRC Press.

Larson, J., Trebitz, A. S., Steinman, A. D., Wiley, M., Carlson-Mazur, M., Pebbles, V., Braun, H., $\&$ Seelbach, P. (2013). Great Lakes rivermouth ecosystems: Scientific synthesis and management implications. Journal of Great Lakes Research, 39, 513-524.

Lawson, D. M., Hall, K. R., Yung, L., \& Enquist, C. A. F. (2017). Building translational ecology communities of practice: Insights from the field. Frontiers in Ecology and the Environment, 15, 569-577.

Levin, S. A., \& Lubchenco, J. (2008). Resilience, robustness, and marine ecosystem-based management. Bioscience, 58, 27-32.

Lipps, J., Harwell, M., Kravitz, M., Lynch, K., Mahoney, M., Pachon, C., \& Pluta, B. (2017) Ecosystem services at contaminated site cleanup, Engineering Forum Issue Paper EPA 542-R17-004. U.S. Environmental Protection Agency, Washington, DC.

Marmet, M., Friel, S., Bell, R., Houweling, T. A., \& Taylor, S. (2008). Closing the gap in a generation: Health equity through action on the social determinants of health. The Lancet, 372, 1661-1669.

Martin, D. M., Mazzotta, M., \& Bousquin, J. (2018). Combining ecosystem services assessment with structured decision making to support ecological restoration planning. Environmental Management, 62, 608-618.

McLain, R. J., \& Lee, R. G. (1996). Adaptive management: Promises and pitfalls. Journal of Environmental Management, 20, 437-448.

Meier, J. R., Lazorchak, J. M., Mills, M., Wernsing, P., \& Baumann, P. (2015). Monitoring exposure of brown bullheads and benthic macroinvertebrates to sediment contaminants in the Ashtabula River before, during, and after remediation. Environmental Toxicology and Chemistry, 34, 1267-1276.

Mollinga, P. P. (2010). Boundary work and the complexity of natural resources management. Crop Science, 50(Supplement 1), S1-S9. 
Mouffe, C. (1999). Deliberative democracy or agonistic pluralism? Social Responsibility, 66, $745-758$.

Minnesota Pollution Control Agency and Wisconsin Department of Natural Resources (1992) The St. Louis River System Remedial Action Plan: Stage One. Minnesota Pollution Control Agency, St. Paul.

National Research Council. (2011). Improving health in the United States: The role of health impact assessment. Washington, DC: National Academies Press.

Olander, L., Polasky, S., Kagan, J. S., Johnston, R. J., Wainger, L., Saah, D., Maguire, L., Boyd, J., $\&$ Yoskowitz, D. (2017). So you want your research to be relevant? Building the bridge between ecosystem services research and practice. Ecosystem Services, 26, 170-182.

Olsson, P., Folke, C., \& Berkes, F. (2004). Adaptive comanagement for building resilience in social-ecological systems. Environmental Management, 34, 874-890.

Palmer, M. A., Bernhardt, E. S., Allan, J. D., Lake, P. S., Alexander, G., Brooks, S., Carr, J., Clayton, S., Dahm, C. N., Follstad Shah, J., Galat, D. L., Loss, S. G., Goodwin, P., Hart, D. D., Hassett, B., Jenskinson, R., Kondolf, G. M., Lave, R., Meyer, J. L., O’Donnell, T. K., Pagano, L., \& Sudduth, E. (2005). Standards for ecologically successful river restoration. Journal of Applied Ecology, 42, 208-217.

Palumbi, S. R., McLeod, K. L., \& Grünbaum, D. (2008). Ecosystems in action: Lessons from marine ecology about recovery, resistance, and reversibility. Bioscience, 58, 33-42.

Partidario, M. R., \& Sheate, W. R. (2013). Knowledge brokerage-potential for increased capacities and shared power in impact assessment. Environmental Impact Assessment Review, 39, 26-36.

Piet, G., Delacámara, G., Kraan, M., Röckmann, G. C., \& Lago, M. (2020). Advancing aquatic ecosystem-based management with full consideration of the social-ecological system. In T. O’Higgins, M. Lago, \& T. H. DeWitt (Eds.), Ecosystem-based management, ecosystem services and aquatic biodiversity: Theory, tools and applications (pp. 17-38). Amsterdam: Springer.

Quigley, R., Furu, L. P., Bond, A., Cave, B., \& Bos, R. (2006). Health impact assessment international best practice principles. Special publication series no 5. Retrieved March 24, 2017 from http://activelivingresearch.org/files/IAIA_HIABestPractice_0.pdf.

Ruckelshaus, M., Klinger, T., Knowlton, M., \& DeMaster, D. P. (2008). Marine ecosystem-based management in practice: Scientific and governance challenges. BioScience, 58, 53-63.

Ruiz-Jaen, M. C., \& Aide, T. M. (2005). Restoration success: How is it being measured? Restoration Ecology, 13, 569-577.

Schoeman, J., Allan, C., \& Finlayson, M. (2014). A new paradigm for water? A comparative review of integrated, adaptive and ecosystem-based water management in the Anthropocene. International Journal of Water Resources Development, 30, 377-390.

Sharpe, L., Hernandez, C., \& Jackson, C. (2020). Prioritizing stakeholders, beneficiaries and environmental attributes: A tool for ecosystem-based management. In T. O'Higgins, M. Lago, \& T. H. DeWitt (Eds.), Ecosystem-based management, ecosystem services and aquatic biodiversity: Theory, tools and applications (pp. 189-212). Amsterdam: Springer.

Sierszen, M. E., Morrice, J. A., Trebitz, A. S., \& Hoffman, J. C. (2012). A review of selected ecosystem services provided by coastal wetlands of the Laurentian Great Lakes. Aquatic Ecosystem Health and Management, 15, 92-106.

Slocombe, D. S. (1993). Implementing ecosystem-based management. Bioscience, 43, 612-621.

Slocombe, D. S. (1998). Defining goals and criteria for ecosystem-based management. Environmental Management, 22, 483-493.

Turner, M. D. (2014). Political ecology I: An alliance with resilience? Progress in Human Geography, 38, 616-623.

USEPA. (2019). Kingsbury bay and grassy point: A health impact assessment. Report (in preparation).

Wall, T. U., McNie, E., \& Garfin, G. M. (2017). Use-inspired science: Making science usable by and useful to decision makers. Frontiers in Ecology and the Environment, 15, 551-559. 
Williams, K. C. (2015). Building bridges in the Great Lakes: How objects and organization facilitate collaboration across boundaries. Journal of Great Lakes Research, 41, 180-187.

Williams, K. C., \& Hoffman, J. C. (2020). Learning in Great Lakes Areas of Concern-connecting remediation, restoration, and revitalization. In: J. H. Hartig, \& M. Munawar (Eds.), Restoring Great Lakes Areas of Concern: A story of struggle and success, ecovision world monograph series (in press). East Lansing, MI: Aquatic Ecosystem Health and Management Society.

Williams, K., Hoffman, J., \& French, N. (2019). From remediation to restoration and revitalization: The St. Louis River story. In J. Hartig, G. Krantzberg, J. C. Austin, \& P. McIntyre (Eds.), Great Lakes revival: How restoring polluted waters leads to rebirth of Great Lakes communities (pp. 61-66). Ann Arbor: International Association of Great Lakes Research.

Yee, S., Cicchetti, G., DeWitt, T. H., Harwell, M. C., Jackson, S. K., Pryor, M., Rocha, K., Santavy, D. L., Sharpe, L., \& Shumchenia, E. (2020). The ecosystem services gradient: A descriptive model for identifying thresholds of meaningful change. In T. O'Higgins, M. Lago, \& T. H. DeWitt (Eds.), Ecosystem-based management, ecosystem services and aquatic biodiversity: Theory, tools and applications (pp. 291-308). Amsterdam: Springer.

Open Access This chapter is licensed under the terms of the Creative Commons Attribution 4.0 International License (http://creativecommons.org/licenses/by/4.0/), which permits use, sharing, adaptation, distribution and reproduction in any medium or format, as long as you give appropriate credit to the original author(s) and the source, provide a link to the Creative Commons licence and indicate if changes were made.

The images or other third party material in this chapter are included in the chapter's Creative Commons licence, unless indicated otherwise in a credit line to the material. If material is not included in the chapter's Creative Commons licence and your intended use is not permitted by statutory regulation or exceeds the permitted use, you will need to obtain permission directly from the copyright holder.

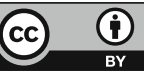

